\title{
Transit Kämpfer: uma proposta de jogo digital para educação no trânsito
}

\author{
Camilla Lara Ferreira ${ }^{1}$, Karoline de Jesus Vieira ${ }^{1}$, Marcos Vinícius Alves de Santana ${ }^{1}$, \\ Charles Soares Pimentel ${ }^{1,2}$ \\ ${ }^{1}$ Escola SESC de Ensino Médio \\ ${ }^{2}$ Programa de Pós-Graduação em Informática - Universidade Federal do Rio de Janeiro \\ \{cferreira2017, kvieira2017,msantana2017, cpimentel\}@escolasesc.com.br
}

\begin{abstract}
This paper presents a proposal for a Serious Game developed by students of the SESC High School in Rio de Janeiro to raise awareness among children and teenagers about traffic safety. The game was developed on the Unity® platform and a case study was conducted to evaluate the proposed activity. The results pointed to the users' engagement and consequent knowledge obtained with the use of the digital game as a teaching-learning object.

Resumo. Este trabalho apresenta uma proposta de Jogo Sério desenvolvido por estudantes da Escola SESC de Ensino Médio, no Rio de Janeiro, para conscientização de crianças e adolescentes quanto à segurança no trânsito. $O$ jogo foi desenvolvido na plataforma Unity ${ }^{\circledR}$ e um estudo de caso foi realizado para avaliar a atividade proposta. Os resultados apontaram para o engajamento dos usuários e consequente conhecimento obtido com a utilização do jogo digital como objeto de ensinoaprendizagem.
\end{abstract}

\section{Introdução}

A escola do século XXI tem como desafio apresentar novas abordagens educacionais para o educando nascido em um contexto informatizado, globalizado e de rede, consequência de uma sociedade cada vez mais tecnológica. O jovem que se encontra em sala de aula é conectado e possui na palma de suas mãos recursos para obter informações com um dinamismo diferente de um estudante do século passado.

No Brasil, a necessidade de se tratar de assuntos que extrapolam o currículo comum é apresentada pela Base Nacional Curricular Comum [BNCC 2019]. Nela, são abordados, além das grandes áreas do conhecimento, temas transversais de importância social, como a cultura digital, a educação ambiental, além da educação no trânsito, que, em específico, ganhou destaque, devido à grande quantidade de mortes causadas por acidentes. Dentro desse quadro alarmante, a UNESCO lançou, em maio de 2011, a Década de Ação pela Segurança no Trânsito 2011-2020, na qual governos, ao redor do mundo, se comprometeram a realizar ações para prevenir acidentes que matam cerca de 1,25 milhões de pessoas por ano [UNESCO 2019].

A partir desse viés, a inclusão de jogos na sala de aula é um potencial recurso de ensinoaprendizagem por proporcionar a compreensão de regras, a busca de solução de problemas, além de colocar o educando em um ambiente virtual que simula a realidade [Freitas e Adamatti, 2016].

Portanto, este trabalho procura contribuir com o tema, apresentando um estudo de caso desenvolvido com crianças e adolescentes entre 7 e 12 anos, no qual se utilizou o jogo digital como instrumento de ensino-aprendizagem de conceitos de educação no trânsito. 
VIII Congresso Brasileiro de Informática na Educação (CBIE 2019)

Anais do XXV Workshop de Informática na Escola (WIE 2019)

Este artigo apresenta a seguinte estrutura, além desta introdução, na seção 2, apresentamos a fundamentação teórica que sustenta a proposta. Na seção 3, é apresentado o projeto proposto. A seção 4, trata da metodologia e da avaliação da abordagem e, por fim, na seção 5, apresentamos as conclusões e apontamos para trabalhos futuros.

\title{
2. Fundamentação teórica
}

\subsection{Educação no trânsito}

A educação no trânsito tornou-se uma importante questão a ser abordada na sociedade, após a expansão do uso de meios de transporte e da popularização de veículos automotores pelas várias camadas sociais. Essa mudança na mobilidade urbana provocou inúmeros efeitos negativos à população, como os problemas de cunho social - acidentes - e de saúde pública.

Para comprovar essas transformações, a Agência Brasil apresentou, em 2019, um importante dado: no primeiro semestre de 2018, houve 19,3 mil mortes por acidente de trânsito no Brasil. Já, em maio do mesmo ano, o relatório do Conselho Federal de Medicina [CFM 2019] mostrou que os acidentes de trânsito causaram cinco mortes no Brasil a cada 1 hora; dentre estes, $60 \%$ deles tendo vítimas entre 15 e 39 anos de idade.

Dessa forma, para amenizar esses dados alarmantes, a Base Nacional Curricular Comum (BNCC) destacou a educação para o trânsito dentre os temas transversais e encontrou nas escolas um importante lugar de debate para crianças, adolescentes e jovens, sendo possível incluí-lo nos jogos digitais. Segundo a Base,

\begin{abstract}
"cabe aos sistemas e redes de ensino, assim como às escolas, em suas respectivas esferas de autonomia e competência, incorporar os currículos e às propostas pedagógicas a abordagem de temas contemporâneos que afetam a vida humana em escala local, regional e global, preferencialmente de forma transversal e integradora. Entre esses temas, destacam-se: [...] a educação para o trânsito (Lei no 9.503/199717) [BNCC 2019]”
\end{abstract}

\subsection{Jogos Sérios}

Um potencial instrumento pedagógico da atualidade advém da fusão entre jogos digitais e educação, denominados jogos sérios, os quais promovem o engajamento dos jovens em questões socialmente relevantes através do entretenimento proporcionado pelos games. Segundo Tolentino et al. (2009), tal tipo de abordagem envolve o estudante no processo educacional, integrando aspectos lúdicos ao ensino, superando, assim, os métodos tradicionais. Dessa forma, o uso crescente da tecnologia no âmbito educacional tem motivado o desenvolvimento de jogos sérios nos últimos anos.

\subsection{Aprendizagem baseada em jogos digitais}

Os jogos digitais têm conquistado cada vez mais espaço na sociedade, principalmente com a criação dos games comerciais como o Pong, considerado o primeiro jogo lucrativo lançado. A partir disso, buscou-se cada vez mais associar tal mercado a amplos campos da sociedade, com o intuito de contribuir, até mesmo, em áreas educacionais, promovendo, assim, um maior engajamento de crianças e adolescentes.

Desse modo, os Jogos Educacionais Digitais (JEDs) têm despertado a atenção de professores e alunos nos últimos anos e, de forma geral, criam uma das áreas de entretenimento que mais se desenvolve na indústria de softwares [Faria et al. 2015]. Estudos mostram que os games e suas características, quando aplicados adequadamente, proporcionam ao usuário um estado de flow (fluxo), que investiga o que ocorre quando a concentração é tão intensa que não há atenção de sobra para pensar em outro assunto [Csiskzentmihalyi 1990]. 
VIII Congresso Brasileiro de Informática na Educação (CBIE 2019)

Anais do XXV Workshop de Informática na Escola (WIE 2019)

\section{Projeto proposto: Transit Kämpfer, jogo digital educacional}

\subsection{Desenvolvimento do Jogo}

O jogo foi construído na plataforma de jogos Unity®, cujos principais recursos são a sua documentação completa com exemplos para toda a sua API, uma ampla comunidade de desenvolvedores, que compartilham experiências e colaboram entre si. Além disso, o sistema de arraste e solte (drag-and-drop) é fácil de ser usado, pois seu conteúdo é listado em uma árvore de opções. A renderização baseada em física atribui textura aos objetos por meio de seu mecanismo de processamento. Por fim, a distribuição multiplataforma pode ser compilada para OSX, Windows ou, até mesmo, WebPlayer (que é executado em um navegador da Web por meio de um plug-in, semelhante ao Adobe Flash) [Craighead et al. 2018].

\subsection{Objetivo do Jogo}

O Transit Kampfer possui um viés social, por isso, o grande objetivo do jogo é educar e orientar o jogador sobre os perigos e cuidados característicos do sistema de trânsito. Por causa disso, o jogador que se encontra em primeira pessoa recebe uma missão no início do jogo e, posteriormente, interage com um quiz gamificado sobre normas básicas das leis de trânsito, para que possa chegar ao destino no menor tempo possível. Entretanto, se o jogador errar parte do questionário, recebe um feedback imediato.

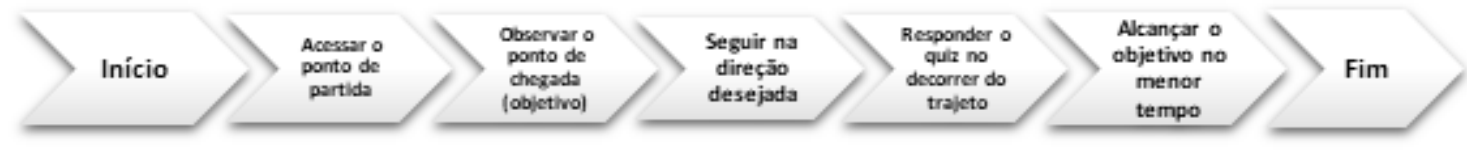

Imagem 1 - Etapas do jogo.

\section{Metodologia e avaliação da abordagem proposta}

A metodologia utilizada para avaliar a proposta foi um estudo de caso com abordagem qualitativa, a partir da realização de teste de usabilidade do jogo Transit Kämpfer com 20 crianças, entre 7 e 12 anos de idade, de uma escola de programação para crianças particular do Rio de Janeiro. O teste de usabilidade teve por objetivo verificar a facilidade que o jogo possui de ser compreendido e manipulado pelos estudantes. Durante os testes, observou-se o engajamento dos usuários, e o estado de fluxo foi notado durante o tempo em que os jogadores interagiram com o jogo. Ao final da experiência de usabilidade, os usuários foram convidados a responder às perguntas apresentadas no Quadro 1.

\begin{tabular}{|c|c|c|}
\hline 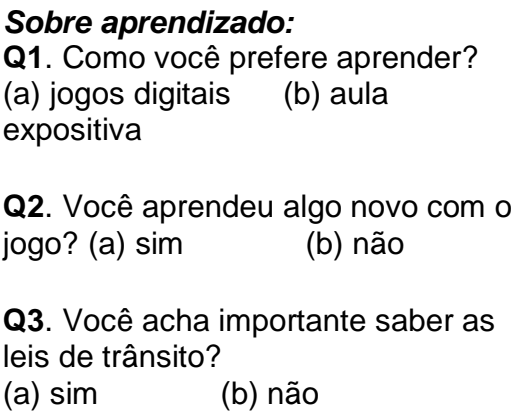 & 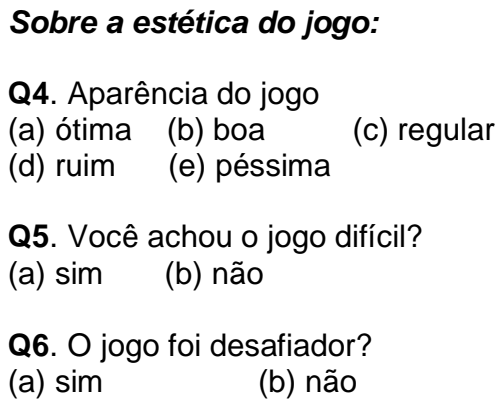 & $\begin{array}{l}\text { Avaliação geral: } \\
\text { Q7. Dê uma nota para o } \\
\text { jogo: } \\
\begin{array}{ll}\text { (a) } 0-3 & \text { b) } 4-6 \\
\text { (c) } 7-8 & \text { (d) } 9-10\end{array}\end{array}$ \\
\hline
\end{tabular}

Quadro 1 - Avaliação do jogo realizada com as crianças que participaram do teste de usabilidade 
As perguntas, com linguagem simples para atender a faixa etária, buscaram apreciar dois importantes pilares que foram tidos como metas durante o desenvolvimento do jogo: o aprendizado proporcionado e a estética do jogo. Além disso, os participantes foram convidados a atribuir uma nota pessoal para o game.

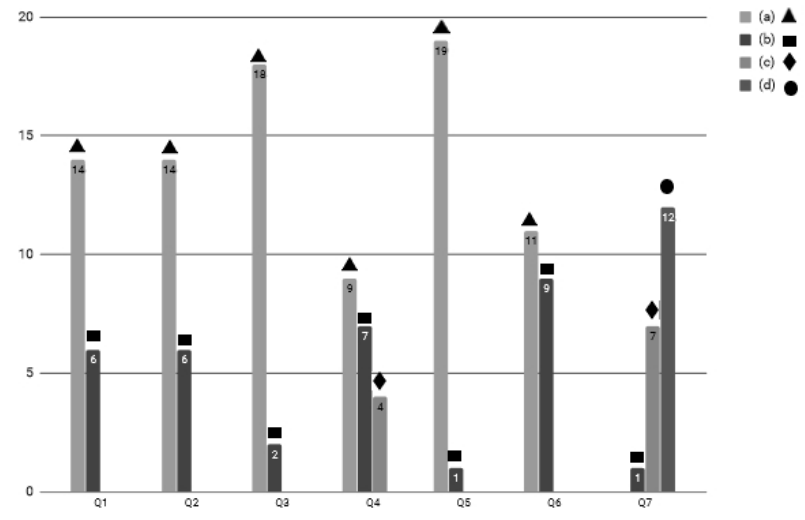

\section{Quadro 2 - Resultado da avaliação realizada pelas crianças no teste de usabilidade}

A observação durante o teste de usabilidade e uma análise das respostas dadas no questionário pelos participantes nos mostram que:

- $\quad$ Os participantes engajaram-se no jogo digital proposto;

- $\quad$ O processo de ensino-aprendizagem promovido pelo jogo digital é um potencial recurso para uma aula dinâmica de introdução à educação no trânsito;

- $\quad$ Os participantes tiveram a oportunidade de aprender sobre leis de trânsito de uma maneira lúdica e desafiadora.

\section{Conclusões}

Dentre os desafios encontrados pela escola do corrente milênio, têm sido objetos de destaque: colocar o aluno no centro de seu aprendizado e proporcionar uma visão crítica de maneira autônoma. Nesse contexto, entre as metodologias que proporcionam o protagonismo estudantil, encontra-se a aprendizagem baseada em jogos digitais. Os JEDs promovem no educando o sentimento de pertencimento ao ambiente de estudo, gerando estado de fluxo, sentimento que fomenta engajamento e envolvimento.

Além disso, a educação no trânsito para crianças e adolescentes é um tema importante na sociedade, visto que é encontrada em destaque na BNCC e no CTB [Código de Trânsito Brasileiro], tornando-se necessário incluir o tema mais efetivamente no ensino da educação básica. Sendo assim, os jogos digitais apresentam-se como um potencial caminho para tratar do assunto, de maneira que o educando seja colocado em um ambiente digital, o qual simula a realidade.

A partir da avaliação realizada com o jogo Transit Kämpfer, constatou-se que os estudantes concordam quanto à potencialidade do uso dele, apesar de terem destacado limitações quanto a alguns elementos do jogo. Como trabalho futuro, essas limitações serão corrigidas, para que uma nova versão do objeto de ensino-aprendizagem seja disponibilizada. 
VIII Congresso Brasileiro de Informática na Educação (CBIE 2019)

Anais do XXV Workshop de Informática na Escola (WIE 2019)

\section{Referências}

Agência Brasil (2019) "Mais de 19,3 mil pessoas morreram em acidentes de trânsito em 6meses", Disponível: <http://agenciabrasil.ebc.com.br/geral/noticia/2018-09/mais-de-193mil-pessoa s-morreram-em-acidentes-de-transito-em-3-meses>. Acesso em: 01 jul. 2019.

Base Nacional Curricular Comum (2019) "Base Nacional Comum Curricular e currículos". Disponível em: <,http://basenacionalcomum.mec.gov.br/images/BNCC_EI_EF_110518_ versaofinal_site.pdf,>. Acesso em: 05 Julho 2019.

Conselho Federal de Medicina (2019) "Em dez anos, acidentes de trânsito consomem quaseR\$3bilhõesdoSUS”. Disponível em: <http://portal.cfm.org.br/index.php?option $=$ com_content $\&$ view $=$ article $\& i d=28254: 2019-05-22-21-49-04 \&$ catid $=3>$. Acesso 03 Julho 2019.

Craighead, J.; Burke, J.; Murph, R. (2018) "Using the Unity Game Engine to Develop SARGE: A Case Study" In: Simulation Workshop at the International Conference on Intelligent Robots and Systems (IROS).

CSISKZENTMIHALYI, M. (1990) "Flow: the psychology of optimal experience". In: New York: HarperCollins Publishers.

Faria, V. P.; Santos, M. A.; Inocêncio, A. C. G.; Parreira Júnior, P. A. (2015) "Apresentação e Avaliação do Jogo "Trânsito Consciente": Um Jogo Educacional Móvel de Auxílio à Conscientização sobre os Riscos de se Dirigir sob Efeito de Álcool”. In: XXI Workshop de Informática na Escola (WIE) - Maceió, AL.

Freitas, V. C. B. e Adamatti, D. (2016) "Educa Direito: Um Jogo Sério para o Ensino de Direito do Trabalho". In: Revista Brasileira de Informática na Educação (RBIE), Volume 24, Número 3.

Tolentino, G.; Oliveira, L. S.; Ventura, A.; Matida, A. B.; Battaglini, C.; Oliveira, R. J. (2009) "Usabilidade de jogos virtuais e frequência cardíaca de usuários. Um estudo comparativo". In: VIII Brazilian Symposium on Games and Digital Entertainment. Rio de Janeiro, RJ, p. 117-120.

UNESCO (2019) “Década de Ação pela Segurança no Trânsito (2011-2020)". Disponível em: $<$ https://nacoesunidas.org /campanha/seguranca-transito/>. Acesso 03 Julho 2019. 